Check for updates

Cite this: RSC Adv., 2018, 8, 5321

\title{
Towards reliable quantification of hydroxyl radicals in the Fenton reaction using chemical probes $\uparrow$
}

\author{
Burgos Castillo Rutely C., (D)*ac Fontmorin Jean-M., ${ }^{a}$ Tang Walter Z., ${ }^{b}$ \\ Dominguez-Benetton Xochitl ${ }^{c d}$ and Sillanpää Mika ${ }^{\text {ab }}$
}

Quantification of hydroxyl radical concentration using two chemical probes was assessed through the Fenton reaction. The probes were 1,2-benzopyrone (coumarin) for fluorescence and 5,5-dimethyl-1-pyrroline-Noxide (DMPO) for electron spin resonance (ESR). The corresponding hydroxylated species, namely 7-hydroxycoumarin (7HC) and 2-hydroxy-5,5-dimethyl-1-pyrroline-N-oxide (DMPO-OH adduct), were monitored by fluorescence and ESR-spin trapping techniques, respectively. The experiments were designed according to the theoretical conditions determined for stable fluorescence and EPR signals. The results demonstrate that: the optimal [chemical probe] : $\left[\mathrm{H}_{2} \mathrm{O}_{2}\right.$ ] ratio predicted by a simplified quasi-steadystate model was in good agreement with the optimal [chemical probe] : $\left[\mathrm{H}_{2} \mathrm{O}_{2}\right]$ ratio observed experimentally for $\left[\mathrm{H}_{2} \mathrm{O}_{2}\right]:\left[\mathrm{Fe}^{2+}\right]=10$, and the proper adjustment of the [chemical probe] : $\left[\mathrm{H}_{2} \mathrm{O}_{2}\right]$ ratio at a given concentration of the Fenton's reagent improves the detected amount of hydroxyl radicals. Finally, using DMPO required a higher concentration compared to coumarin to yield the same amount of ${ }^{\circ} \mathrm{OH}$ detected but resulted in a more reliable probe for detecting ${ }^{\circ} \mathrm{OH}$ under the consideration of this study.

Received 10th December 2017 Accepted 22nd January 2018

DOI: $10.1039 / c 7 r a 13209 c$

rsc.li/rsc-advances
Indirect methods, such as probe-assisted spectroscopic techniques, are helpful to estimate the concentration of ${ }^{\circ} \mathrm{OH} .{ }^{10-13}$ These methods follow the products formed from the reaction between ${ }^{\circ} \mathrm{OH}$ and the chemical probes, namely salicylic acid, 4-hydroxybenzoic acid, $p$-chlorobenzoic acid, phthalhydrazine, atrazine, deethylatrazine, $p$-nitrosodimethylaniline, n-propanol, coumarin, nitroxide compounds, dimethylsulfoxide (DMSO), among others. ${ }^{\mathbf{1 4 , 1 5}}$ Nevertheless, since ${ }^{\circ} \mathrm{OH}$ radicals are non-selective oxidants, a large number of by-products have been detected when using those probes. ${ }^{14,16,17}$

Ideally, chemical probes to detect radicals like ${ }^{\circ} \mathrm{OH}$ would readily react with the targeted radical while remaining significantly unaffected by subsequent reactions, besides being innocuous, well-characterized and economical. ${ }^{18,19}$ Additionally, they should provide reproducibility and repeatability in the analysis of ${ }^{\circ} \mathrm{OH} .{ }^{14}$ In other words, reliable detection and quantification of ${ }^{\circ} \mathrm{OH}$ require identification of conditions where the chemical probes are sensitive and selective to ${ }^{\circ} \mathrm{OH}$ while the formation of byproducts is limited, and wherein the reaction products to be measured do not react significantly with excess 'OH or other reactive oxygen species (ROS) present in the media. Thus, providing long-term stability. The use of chemical probes for ${ }^{\circ} \mathrm{OH}$ detection and quantification should rely on the understanding of their chemical properties, their kinetic behaviour and their functionality in the conditions of interest.

The chemical environment in which ${ }^{\circ} \mathrm{OH}$ are generated is of paramount relevance. ${ }^{2}$ Its components may have an impact on the scavenging, decomposition or even on the acceleration of

${ }^{\circ} \mathrm{OH}$ production. For instance, even throughout a well-

\footnotetext{
Laboratory of Green Chemistry, School of Engineering Science, Lappeenranta rutely.burgos.castillo@lut.fi

${ }^{b}$ Department of Civil and Environmental Engineering, Florida International University, Miami, FL-33174, USA

${ }^{c}$ Separation and Conversion Technologies, Flemish Institute for Technological Research (VITO), Boeretang 200, 2400, Mol, Belgium

${ }^{d}$ SIM vzw, Technologiepark 935, BE-9052 Zwijnaarde, Belgium

$\dagger$ Electronic supplementary information (ESI) available. See DOI: $10.1039 / \mathrm{c} 7 \mathrm{ra} 13209 \mathrm{c}$
} 
controlled Fenton's reaction (reaction (1)), wherein ferrous ions act with hydrogen peroxide to generate ${ }^{\circ} \mathrm{OH}$, these effects have been evidenced. Peña et al. discussed the importance of the role that excess hydrogen peroxide plays as a scavenger of ${ }^{\circ} \mathrm{OH}$ (reaction (3)), thus decreasing their concentration at a faster rate than they are generated through the Fenton reaction. In addition, ferric and ferrous iron ions react with hydrogen peroxide (reaction (2) and (4)), ${ }^{20}$ thus having an ultimate impact on the generation, detection, and quantification of ${ }^{\bullet} \mathrm{OH} .^{21}$

$$
\begin{gathered}
\mathrm{Fe}^{2+}+\mathrm{H}_{2} \mathrm{O}_{2} \rightarrow \mathrm{Fe}^{3+}+{ }^{\cdot} \mathrm{OH}+\mathrm{OH}^{-}, k_{i}=76 \mathrm{~mol} \mathrm{~L}^{-1} \mathrm{~s}^{-1} \\
\mathrm{Fe}^{2+}+{ }^{\cdot} \mathrm{OH} \rightarrow \mathrm{Fe}^{3+}+\mathrm{OH}^{-}, k_{t 1}=3 \times 10^{8} \mathrm{~mol} \mathrm{~L}^{-1} \mathrm{~s}^{-1} \\
\mathrm{H}_{2} \mathrm{O}_{2}+{ }^{\circ} \mathrm{OH} \rightarrow \mathrm{HO}_{2}{ }^{-}+\mathrm{H}_{2} \mathrm{O}, k_{t 2}=2.7 \times 10^{7} \mathrm{~mol} \mathrm{~L}^{-1} \mathrm{~s}^{-1} \\
\mathrm{Fe}^{3+}+\mathrm{H}_{2} \mathrm{O}_{2} \rightarrow \mathrm{Fe}^{2+}+\mathrm{H}^{+}+\mathrm{HO}_{2} \cdot \\
k_{t 3}=3.1 \times 10^{-3} \mathrm{~mol} \mathrm{~L}^{-1} \mathrm{~s}^{-1}
\end{gathered}
$$

Ciotti et al. observed an effect of the $\left[\mathrm{Fe}^{2+}\right]:\left[\mathrm{H}_{2} \mathrm{O}_{2}\right]$ ratio on the amount of radicals formed. Although they employed a mathematical model to explain this behaviour, they did not consider the need of reaching a steady state to ensure the reliability of their method to quantify hydroxyl radicals, ${ }^{22}$ which leads to inaccurate results.

On the other hand, the work of Lindsey and Tarr ${ }^{11}$ pointed out at the possibility of finding optimal conditions in Fenton systems to successfully use chemical probes for ${ }^{\circ} \mathrm{OH}$ detection and quantification. However, since then, only a few works have attempted to rationalize the use of organic chemical probes in Fenton-based processes.

Organic chemical probes such as $\mathrm{DMPO}^{23,24}$ and coumarin $^{\mathbf{1 0 , 2 5}}$ exhibit low toxicity and good sensitivity, but their conditions of use have not yet rendered high selectivity in Fenton-based systems, showing variable behaviour from sample to sample or method to method, which needs to be calibrated every time. ${ }^{14}$ In the majority of studies, the probe concentration appears to be critical; ${ }^{\mathbf{1 1 , 1 3 , 2 6}}$ skewed results can occur when chemical probes are used in concentrations at which the probability of reaction with the ${ }^{\circ} \mathrm{OH}$ available is either low or very high. ${ }^{11,15,16,26,27}$ Abou et al. investigated the use of DMSO in an electro-Fenton system. They concluded that DMSO would not be an appropriate probe because of the electrode reactions of DMSO. ${ }^{15}$

Furthermore, the sensitivity and reliability of organic chemical probes in the presence of complex matrices involving metals, anions, and cations like in AOP conditions, is not thoroughly assessed; thus, determining the concentration of radicals is still a challenging issue. Therefore, it is of significant value to investigate and predict systematically how, for specific systems and chemical environments, the key factors such as the concentrations of the major reactants and the chemical probe affect the detection of ${ }^{\circ} \mathrm{OH}$ under different operating conditions.

This study was designed as an approach to analyse and to establish appropriate relations between key parameters that influence the quantification of ${ }^{\circ} \mathrm{OH}$ : the concentrations of the
Fenton's reagent and chemical probe. The detection of ${ }^{\bullet} \mathrm{OH}$ was performed using two well-known chemical probes, namely coumarin and 5,5-dimethyl-1-pyrroline-N-oxide (DMPO). This information is useful to further understand in which conditions 'OH detection and quantification can be feasible under ideal performance of Fenton systems (i.e., $\mathrm{pH} 3$ ). ${ }^{\mathbf{2 8 - 3 1}}$ Finally, this study may be immediately extrapolated to systematically investigate the use of other chemical probes which can reduce time and resources.

\section{Experimental section}

\section{Chemicals}

Ferrous sulfate heptahydrate $\left(\mathrm{FeSO}_{4} \cdot 7 \mathrm{H}_{2} \mathrm{O}\right)$ and hydrogen peroxide $\left(\mathrm{H}_{2} \mathrm{O}_{2}\right)$ were purchased from Merck (Darmstadt, Germany). 4-Hydroxy-2,2,6,6-tetramethylpiperidin-1-oxyl (TEMPOL), 1,2-benzopyrone (coumarin) and 7-hydroxycoumarin (umbelliferone) and catalase were purchased from SigmaAldrich (Darmstadt, Germany). 5,5-Dimethyl-1-pyrroline-Noxide (DMPO) was provided by Cayman Chemical Company (Ann Arbor, USA). All reagents were of analytical grade and were used without further purification. The concentrations of stock solutions for Fenton reagents were: $4.5 \mathrm{M} \mathrm{H}_{2} \mathrm{O}_{2}, 0.05 \mathrm{M}$ $\mathrm{FeSO}_{4} \cdot 7 \mathrm{H}_{2} \mathrm{O}, 1 \mathrm{M}$ DMPO and $0.008 \mathrm{M}$ coumarin. The $\mathrm{pH}$ of all stock solutions was adjusted to $3.0 \pm 0.2$ using concentrated sulfuric acid. All chemical solutions were prepared using ultrapure water produced with a Millipore Milli-Q system and stored in amber flasks at laboratory $+4{ }^{\circ} \mathrm{C}$.

\section{Sample preparation}

Electron Spin Resonance (ESR) experiments were conducted with $\mathrm{H}_{2} \mathrm{O}_{2}$ and $\mathrm{Fe}^{2+}$ concentrations varying from $0.1 \mathrm{mM}$ to $10 \mathrm{mM}$, and from $0.001 \mathrm{mM}$ to $1 \mathrm{mM}$, respectively. DMPO was employed at a fixed concentration of $100 \mathrm{mM}$. Different ratios of $\left[\mathrm{H}_{2} \mathrm{O}_{2}\right]:\left[\mathrm{Fe}^{2+}\right]$, i.e., $10: 1 ; 100: 1 ; 1000: 1 ; 10000: 1$, and $100000: 1$, were tested. Fenton reactions were performed by mixing reagents using a vortex, in the following order: ultrapure water (adjusted to $\mathrm{pH} 3.0 \pm 0.2$ using concentrated sulfuric acid), $\mathrm{H}_{2} \mathrm{O}_{2}$, DMPO, and $\mathrm{FeSO}_{4} \cdot 7 \mathrm{H}_{2} \mathrm{O}$ (total volume: 2 $\mathrm{mL}$ ). The mixed reagents were allowed to react in the dark and samples were taken and analysed at times specified in the Results and discussion section.

Fluorescence experiments were conducted with $\mathrm{H}_{2} \mathrm{O}_{2}, \mathrm{Fe}^{2+}$, and coumarin concentrations varying from $1 \mathrm{mM}$ to $100 \mathrm{mM}$, $0.001 \mathrm{mM}$ to $10 \mathrm{mM}$, and $1 \mathrm{mM}$ to $4 \mathrm{mM}$, respectively, using different ratios of $\left[\mathrm{H}_{2} \mathrm{O}_{2}\right]:\left[\mathrm{Fe}^{2+}\right]$, i.e., $10: 1 ; 100: 1$, and $1000: 1$. The difference in the $\left[\mathrm{H}_{2} \mathrm{O}_{2}\right]:\left[\mathrm{Fe}^{2+}\right]$ ratios employed for detection with DMPO and coumarin is due to the lower solubility of coumarin compared to DMPO, as well as due to the difference in sensitivity of the fluorescence method, which is higher for coumarin. Fenton reactions were prepared by mixing reagents in desired proportions using a vortex, in the following order: ultra-pure water (adjusted to $\mathrm{pH} 3.0 \pm 0.2$ using concentrated sulfuric acid), $\mathrm{H}_{2} \mathrm{O}_{2}$, coumarin, and $\mathrm{FeSO}_{4} \cdot 7 \mathrm{H}_{2} \mathrm{O}$ (volume: $2.5 \mathrm{~mL}$ ). Blank experiments were recorded to verify that both ESR and fluorescence signals resulted from the 
reaction between the chemical probe and ${ }^{\circ} \mathrm{OH}$. The mixed reagents were allowed to react in the dark and samples were taken at times presented in the Results and discussion section. All samples for DMPO-OH adduct were quenched by adding 100 $\mu \mathrm{L}$ of catalase dissolution immediately after taking the sample to achieve a final concentration of $0.2 \mathrm{mg} \mathrm{L}^{-1}, \mathrm{pH}$ of those samples increased to $5-6 .^{24}$ Fluorescence samples were measured immediately thus no quencher was used as catalase decreased the signal when used.

\section{Fluorescence and ESR analysis}

Fluorescence measurements were performed using a Cary Eclipse spectrophotometer from Varian Corporation (Palo Alto, California, USA). The excitation wavelength was set at $340 \mathrm{~nm}$, and the emission wavelength enveloped at $456 \pm 2 \mathrm{~nm}$; the excitation and emission slits were 10 and $5 \mathrm{~nm}$, respectively. A calibration curve using 7-hydroxycoumarin (7HC) as a standard was constructed to quantify the $7 \mathrm{HC}$ formed as a result of the hydroxylation reaction between coumarin and ${ }^{\circ} \mathrm{OH}$ (reaction (5)). All samples were analysed at least in triplicate to build the calibration curves and the Fenton problem samples described in Table 2 were analysed at least in duplicate. All plots were prepared using Origin 2015.

$$
\text { Coumarin }+\cdot \mathrm{OH} \stackrel{k_{\mathrm{C}}}{\longrightarrow} 7 \mathrm{HC}, k_{\mathrm{C}}=5.6 \times 10^{9} \mathrm{M}^{-1} \mathrm{~s}^{-1}
$$

The concentration of the DMPO-OH adduct, generated from the reaction between DMPO and ${ }^{\circ} \mathrm{OH}$ (reaction (6)), was measured with an ESR spectrometer CMS-8400 from ADANI, Minsk, Belarus. The ESR spectrometer operated at $9.450 \mathrm{GHz}$ with $0.100 \mathrm{mT}$ magnetic field modulation. The instrumental parameters were: center field $336.5 \pm 6.0 \mathrm{mT}$, power attenuation $10 \mathrm{~dB}$, sweep time $100 \mathrm{~s}$, and 4096 data points.

$$
\mathrm{DMPO}+{ }^{\circ} \mathrm{OH} \stackrel{k_{\mathrm{D}}}{\longrightarrow} \mathrm{DMPO}-\mathrm{OH}, k_{\mathrm{D}}=3.4 \times 10^{9} \mathrm{M}^{-1} \mathrm{~s}^{-1}
$$

To analyse quantitatively the DMPO-OH adduct signal intensity, TEMPOL was used as the standard. TEMPOL was selected as an ESR standard due to its relative stability and solubility in water. ${ }^{32}$ From ESR spectra, DMPO-OH adduct and TEMPOL intensities were measured as the peak-to-peak amplitude. TEMPOL concentrations were varied from $2.5 \times$ $10^{-6} \mathrm{M}$ to $12.5 \times 10^{-6} \mathrm{M}$ in the same conditions as Fenton reactions, and both samples and standards were measured under non-saturating conditions. ESR parameters of the DMPO$\mathrm{OH}$ adduct and TEMPOL were determined using EasySpin software $5.0 .^{33}$ When required, dilution factors were applied to the samples. All plots were prepared using Origin 2015 and MATLAB R2015b software.

\section{Calibration curves}

The concentration of $7 \mathrm{HC}$ was quantified from the fluorescence intensity and was used to determine the ${ }^{\circ} \mathrm{OH}$ concentration. The reaction yield between coumarin and ${ }^{\circ} \mathrm{OH}$ to form $7 \mathrm{HC}$ (reaction (5)) was reported as $4.7 \%$ by Newton and Milligan. ${ }^{17}$ The fraction of ${ }^{\bullet} \mathrm{OH}$ not leading to $7 \mathrm{HC}$ generates other hydroxylated compounds which are not fluorescent, and are thus not detected by the technique used. ${ }^{17,34}$ Therefore the yield fraction of 4.7\% was taken into account for the calculations of radicals generated during the Fenton experiments. Typical spectra of the fluorescence intensity of 7HC standard and the constructed calibration curve are described in Fig. S1. $\dagger$

The ESR signal of the DMPO-OH adduct was expressed relative to the concentration of the stable radical TEMPOL. ${ }^{35} \mathrm{All}$ ESR spectra exhibited typical hyperfine coupling constants of the DMPO-OH quartet $\left(a_{\beta \mathrm{H}}=a_{\mathrm{N}}=1.47 \mathrm{mT}\right)$ and the TEMPOL triplet $\left(a_{\mathrm{N}}=1.68 \mathrm{mT}\right) .^{35,36}$ The ESR peak-to-peak intensity of TEMPOL increased with the increasing dosage. ESR spectra recorded for DMPO-OH adduct and TEMPOL and the built calibration curve are depicted in Fig. $\mathrm{S} 2$ and $\mathrm{S} 3, \dagger$ respectively.

\section{Equations for the determination of the chemical probe concentration}

To gain insight into the use of chemical probes for measuring 'OH generation, eqn (7) and (8)-derived from a kinetic model proposed in our earlier work-were used. The agreement between the theoretical [chemical probe] : $\left[\mathrm{H}_{2} \mathrm{O}_{2}\right]$ ratio against the experimental one was analysed, in order to obtain a reliable signal by either fluorescence or ESR. ${ }^{24}$

The model assumed quasi-steady-state concentrations. As a consequence, some important conditions must be satisfied in order to generate stable signals: (i) the rate of change of the reaction product (i.e., DMPO-OH adduct, 7HC) with respect to time approaches zero; ${ }^{24}$ (ii) the rate of change of the reaction product with respect to time is not a function of the concentration of the chemical probe; ${ }^{24}$ (iii) the reaction product to be followed does not degrade significantly during the time frame of the analysis; otherwise, the conditions are not favorable for -OH detection. ${ }^{\mathbf{1 1}, \mathbf{1 7}, 23}$

Eqn (7) and (8) were developed in terms of elementary reactions for coumarin and DMPO, respectively. The respective contributions of the reaction rates from side reactions were set at zero. Thus these equations are simplified to reflect the contribution of the $\left[\mathrm{H}_{2} \mathrm{O}_{2}\right]:\left[\mathrm{Fe}^{2+}\right]$ ratio and the chemical probe concentration to produce a constant signal under quasi-steadystate conditions, as previously demonstrated. ${ }^{24}$

$$
\begin{gathered}
\frac{[\text { Coumarin }]}{\left[\mathrm{H}_{2} \mathrm{O}_{2}\right]} \gg \frac{k_{t 1}\left[\mathrm{Fe}^{2+}\right]}{k_{\mathrm{C}}\left[\mathrm{H}_{2} \mathrm{O}_{2}\right]}+\frac{k_{t 2}}{k_{\mathrm{C}}} \\
\frac{[\mathrm{DMPO}]}{\left[\mathrm{H}_{2} \mathrm{O}_{2}\right]} \gg \frac{k_{t 1}\left[\mathrm{Fe}^{2+}\right]}{k_{\mathrm{D}}\left[\mathrm{H}_{2} \mathrm{O}_{2}\right]}+\frac{k_{t 2}}{k_{\mathrm{D}}}
\end{gathered}
$$

where: $k_{t 1}$ (rate constant of reaction (2)), $k_{t 2}$ (rate constant of reaction (3)), are rate constants of ${ }^{\circ} \mathrm{OH}$ quenching reactions in the Fenton mechanism; ${ }^{23} k_{\mathrm{C}}\left(5.6 \times 10^{9} \mathrm{M}^{-1} \mathrm{~s}^{-1}\right), k_{\mathrm{D}}\left(3.4 \times 10^{9}\right.$ $\left.\mathrm{M}^{-1} \mathrm{~s}^{-1}\right)$ are formation rate constants of $7 \mathrm{HC}$ and $\mathrm{DMPO}-\mathrm{OH}$ adduct, respectively.

According to the discussions in our previous work, ${ }^{24}$ to obtain stable signals by fluorescence and ESR, the left-hand ratios from eqn (7) and (8) ([chemical probe]: $\left[\mathrm{H}_{2} \mathrm{O}_{2}\right]$ ) should be significantly greater, i.e., by at least two to three orders of 
magnitude higher than the corresponding right-hand ratios. In the case of DMPO, this hypothesis was already confirmed with initial concentrations of $1 \mathrm{mM} \mathrm{H}_{2} \mathrm{O}_{2}$ and $0.1 \mathrm{mM} \mathrm{Fe}^{2+}$ (i.e., $\left[\mathrm{H}_{2} \mathrm{O}_{2}\right]:\left[\mathrm{Fe}^{2+}\right]=10$ and right-hand ratio of eqn (8) equals 0.0168). Experiments confirmed that [DMPO]: $\left[\mathrm{H}_{2} \mathrm{O}_{2}\right]$ ratio should be at minimum 16.8 in order to obtain a stable DMPO$\mathrm{OH}$ adduct signal. ${ }^{24}$ However, the susceptibility of the DMPO signal to change with the probe concentration was not previously validated, and thus the [chemical probe]: $\left[\mathrm{H}_{2} \mathrm{O}_{2}\right]$ ratios and that the amount Fenton's reagent can be still optimized. Besides, this work makes progress beyond the current state of the art by: (1) providing further analysis to establish the suitable values of chemical probe which can render a stable analytical response, and (2) finding optimal concentrations of iron that can be used as catalyst for Fenton reactions in the conditions studied.

Table 1 shows the theoretical [chemical probe]: $\left[\mathrm{H}_{2} \mathrm{O}_{2}\right]$ values predicted, at different Fenton's reagent ratios using $1 \mathrm{mM}$ coumarin. In these calculations, the $\mathrm{Fe}^{2+}$ concentration was varied at given concentrations of $\mathrm{H}_{2} \mathrm{O}_{2}$ (from $10^{-2} \mathrm{M}$ to $10^{-4}$ M). For example, for $\left[\mathrm{H}_{2} \mathrm{O}_{2}\right]:\left[\mathrm{Fe}^{2+}\right]=10$, the threshold [coumarin] : $\left[\mathrm{H}_{2} \mathrm{O}_{2}\right]$ ratio is 1.02 (Table 1) which was taken as two orders of magnitude higher than the value calculated from eqn (7) (i.e. 0.0102). Thus the experiments were designed and carried out in order to validate the hypothesis suggested by the theoretical model and to verify whether this model can also be applied to coumarin.

\section{Results and discussion}

\section{Validation of the equations proposed to determine optimal chemical probe concentration}

To validate the conditions suggested from eqn (7) in Fenton systems, three different sets of experiments were carried out by varying the Fenton's reagent ratio and coumarin concentration. The first set of experiments measured the concentration of $7 \mathrm{HC}$ with respect to time, by varying coumarin concentration. The conditions applied in this section are described in Table 2. The experiments lasted for up to $60 \mathrm{~min}$ at a fixed $\left[\mathrm{H}_{2} \mathrm{O}_{2}\right]:\left[\mathrm{Fe}^{2+}\right]$ ratio of 10 and varying coumarin concentrations from $0.5 \mathrm{mM}$ to $4 \mathrm{mM}$ (Fig. 1). According to the theoretical model described above (eqn (7)), the optimal [coumarin] : $\left[\mathrm{H}_{2} \mathrm{O}_{2}\right]$ ratio was expected to be at minimum 1 to 10 . Experiments were carried out to validate the values calculated by the model.

Table 1 Theoretical [coumarin] : $\left[\mathrm{H}_{2} \mathrm{O}_{2}\right]$ ratios predicted from eqn (7), for a set of proposed $\left[\mathrm{H}_{2} \mathrm{O}_{2}\right]:\left[\mathrm{Fe}^{2+}\right]$ ratios

\begin{tabular}{ll}
\hline Ratio & Theoretical ratio \\
\hline$\left[\mathrm{H}_{2} \mathrm{O}_{2}\right]:\left[\mathrm{Fe}^{2+}\right]$ & {$[$ Coumarin $]:\left[\mathrm{H}_{2} \mathrm{O}_{2}\right]^{a}$} \\
\hline 10 & 1.02 \\
100 & 0.54 \\
1000 & 0.49 \\
${ }^{a}$ From right hand side of eqn (7). &
\end{tabular}

Table 2 Fenton's reagent and coumarin concentrations used in this study

\begin{tabular}{lllll}
\hline Condition & $\begin{array}{l}{\left[\mathrm{H}_{2} \mathrm{O}_{2}\right]} \\
(\mathrm{mM})\end{array}$ & $\begin{array}{l}{\left[\mathrm{Fe}^{2+}\right]} \\
(\mathrm{mM})\end{array}$ & $\begin{array}{l}{[\text { Coumarin }]} \\
(\mathrm{mM})\end{array}$ & {$[$ Coumarin] $]\left[\mathrm{H}_{2} \mathrm{O}_{2}\right]$} \\
\hline Fenton A & 1 & 0.1 & 0.5 & 0.5 \\
Fenton B & 1 & 0.1 & 1 & 1 \\
Fenton C & 1 & 0.1 & 2 & 2 \\
Fenton D & 1 & 0.1 & 4 & 4 \\
Fenton E & 1 & 0.1 & 0.05 & 0.05 \\
Fenton F & 1 & 0.1 & 0.1 & 0.1 \\
Fenton G & 0.1 & 0.01 & 0.1 & 1 \\
Fenton H & 0.1 & 0.01 & 0.5 & 5 \\
Fenton I & 0.1 & 0.01 & 1 & 10 \\
Fenton J & 10 & 0.1 & 1 & 0.1 \\
Fenton K & 1 & 0.01 & 1 & 1 \\
Fenton L & 10 & 0.01 & 1 & 0.1 \\
Fenton M & 10 & 1 & 1 & 0.1 \\
Fenton N & 100 & 0.1 & 1 & 0.01
\end{tabular}

In principle, it may be expected that the formation of ${ }^{\circ} \mathrm{OH}$ would occur at the same rate in all these four systems (A-D), given that the same concentrations and ratios of Fenton's reagent were used. However, it has been discussed that changes in initial probe concentration will result in a shift in probe response even at constant radical flux. ${ }^{18}$ Thus, these results suggest that once the ${ }^{\circ} \mathrm{OH}$ are formed, it is the rate of their reaction with coumarin which is, in fact different as the coumarin concentration changes, presumably driven by mass transfer limitations. Because for every molecule of coumarin and ${ }^{\circ} \mathrm{OH}$ to react, these must come into intimate contact with each other. Although good mixing increases the chances of interaction, the concentration of coumarin molecules implies a delayed rate for their reaction with ${ }^{\circ} \mathrm{OH}$ when coumarin appears to be in large excess (i.e., systems $\mathrm{C}$ and D). As depicted in Fig. 1, with condition A, the chemical probe concentration appeared to be underdosed and resulted in a non-steady state concentration of $7 \mathrm{HC}$. In this system, the signal decreased fast after the first $20 \mathrm{~min}$ of reaction.

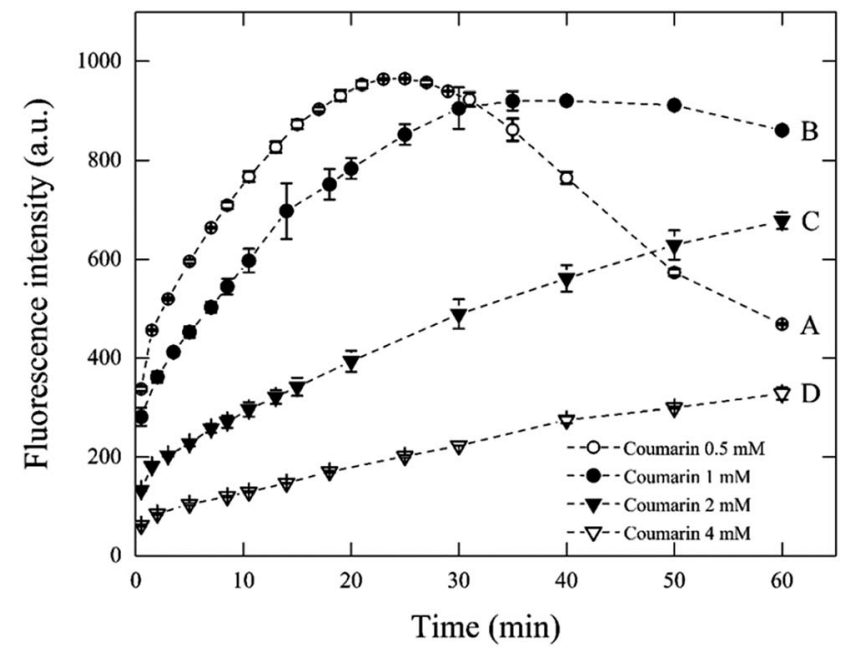

Fig. 1 Effect of coumarin concentration on fluorescence intensity during $60 \mathrm{~min}$ for Fenton reaction with $1 \mathrm{mM} \mathrm{H}_{2} \mathrm{O}_{2}$ and $0.1 \mathrm{mM} \mathrm{Fe}^{2+}$. 
It is inferred that coumarin is first hydroxylated into $7 \mathrm{HC}$ during the first $20 \mathrm{~min}$. Yet, the disappearance of $7 \mathrm{HC}$ can be attributed to the relative excess of homogeneous reactive oxygen species (mainly ${ }^{\circ} \mathrm{OH}$, and to a lesser extent $\mathrm{H}_{2} \mathrm{O}_{2}, \mathrm{HO}_{2}{ }^{\circ}$ ) which can further attack the $\pi$-electron-rich position of the hydroxylated primary byproducts formed to render different molecules than 7HC which either may not fluoresce or may be easily degraded to smaller molecules such as carboxylic acids. ${ }^{\mathbf{1 0 , 2 6 , 3 7 , 3 8}}$ The swift degradation of $7 \mathrm{HC}$ is feasible, and the conditions are here clearly identified. This is a fundamental step to prevent 7HC to react significantly with ${ }^{\circ} \mathrm{OH}$ for reliable measurements.

The fluorescence response of system B ([coumarin] : $\left[\mathrm{H}_{2} \mathrm{O}_{2}\right]$ ratio of 1), reached a maximum value after $30 \mathrm{~min}$, then remained relatively stable until $50 \mathrm{~min}$ in contrast to the other tests. These results may indicate the establishment of a quasisteady-state concentration of $7 \mathrm{HC}$, wherein a $1 \mathrm{mM}$ coumarin concentration would be suitable for the detection of radicals up to $30 \mathrm{~min}$, where the accumulated concentration of $7 \mathrm{HC}$ could be considered constant and maximum.

From these data, the hypothetical [coumarin] : $\left[\mathrm{H}_{2} \mathrm{O}_{2}\right]$ ratio calculated from the theoretical model (eqn (7)) appears to be in good agreement with the experimental one, i.e., for $\left[\mathrm{H}_{2} \mathrm{O}_{2}\right]:\left[\mathrm{Fe}^{2+}\right]=10$, the right-hand ratio of eqn (7) equals 0.0102 which means that [coumarin]: $\left[\mathrm{H}_{2} \mathrm{O}_{2}\right]$ must be at minimum 1.02 in order to obtain a stable fluorescence signal.

In conditions $\mathrm{C}$ and $\mathrm{D}$ (i.e., [coumarin]: $\left[\mathrm{H}_{2} \mathrm{O}_{2}\right]>1$ ), the amount of 7HC was lower, thus using a higher coumarin concentration does not result in more efficient radical detection. This behaviour has been previously shown. ${ }^{26}$ However, it was overlooked by the authors, and hence it remained unexplored.

In general, as the same concentration and ratio of Fenton's reagent were kept constant in all systems, the rate-limiting step of the process is the reaction of ${ }^{\circ} \mathrm{OH}$ with coumarin. If there would be no other effects, then all cases should give the same response up to the point where either coumarin or ${ }^{\circ} \mathrm{OH}$ are exhausted. Moreover, the hypothesis derived from our model (eqn (7)) suggests that an optimum coumarin concentration to detect ${ }^{\circ} \mathrm{OH}$ must be established. The effect of coumarin concentration can be explained as follows. First, when coumarin concentration is higher as in $\mathrm{C}$ and $\mathrm{D}$, part of the $7 \mathrm{HC}$ concentration may react rapidly with ${ }^{\circ} \mathrm{OH}$ and compete with reaction of ${ }^{\circ} \mathrm{OH}$ with coumarin. ${ }^{\circ} \mathrm{OH}$ can be consumed by coumarin, coumarin byproducts and scavengers. Thus, the concentration of ${ }^{\circ} \mathrm{OH},\left[{ }^{\circ} \mathrm{OH}\right]$, can change with time, as the concentration of organics change. Therefore, the fluorescence response may be poorer-given that it will take a longer time for coumarin to effectively collide with a ${ }^{\bullet} \mathrm{OH}$ molecule; otherwise, part of the emission energy of the fluorophores may decrease by self-quenching. ${ }^{18,39,40}$ As a consequence, a decreasing fluorescence signal resulted when coumarin increased from $2 \mathrm{mM}$ (system C) to $4 \mathrm{mM}$ (system $\mathrm{D}$ ). At optimal coumarin concentrations, which may be between systems B and C, the quasisteady-state is promoted as a stoichiometric ratio of coumarin is used. Finally, when coumarin concentration is lower, it gets rapidly exhausted from the reaction system A. Thus the fluorescence signal decay was observed, as explained before. From, these kinetic profiles we can conclude the following statements in which the profiles from Fig. 1 seem to exhibit four kinetic regimes: (i) very fast kinetic effect on the first two minutes, (ii) after the first two minutes and up to a certain point around $20 \mathrm{~min}$, the profile is specific for each case, (iii) after the first $20 \mathrm{~min}$, it appears a change in slope to a slower rate as coumarin concentration increases, which leads to an inflection point (system A), steady state (system B) or to a decrease in rate (systems C and D), (iv) the slower rate, may be due to a low concentration of coumarin (after $20 \mathrm{~min}$ ) which may promote the reaction between $7 \mathrm{HC}$ and excess radicals. This fact is evident in the system A.

To further assess the effect of the coumarin concentration and the role of the initial concentration of Fenton's reagent on the kinetic profile, a second set of experiments was carried out using conditions E-I, with $\left[\mathrm{H}_{2} \mathrm{O}_{2}\right]:\left[\mathrm{Fe}^{2+}\right]$ kept at a value of 10 (Fig. 2). In those tests, the fluorescence signal evolved into a combination of two opposite trends and was dependent on both the initial coumarin concentration and the initial concentration of Fenton's reagent. As it was expected with conditions $\mathrm{E}$ and $\mathrm{F}$ (Fig. 2I), the fluorescence intensity decreased, which occurred during the first $15 \mathrm{~min}$. It confirms that the underdosed coumarin is rapidly depleted by ${ }^{\circ} \mathrm{OH}$ to form $7 \mathrm{HC}$, the last being further hydroxylated to nonfluorescent species by ${ }^{\circ} \mathrm{OH}$ that kept forming as described previously.

When the concentration of Fenton's reagent was reduced by a factor of ten (i.e., $0.1 \mathrm{mM} \mathrm{H}_{2} \mathrm{O}_{2}$ and $0.01 \mathrm{mM} \mathrm{Fe}^{2+}$, Fig. 2II) and the coumarin concentration used at conditions G-I, corresponded to $0.1 \mathrm{mM}, 0.5 \mathrm{mM}$, and $1 \mathrm{mM}$, respectively, the fluorescence signals showed a tendency to increase through time. However, these systems did not reach a quasi-steady-state concentration of $7 \mathrm{HC}$ during $60 \mathrm{~min}$ of reaction. In addition, as the coumarin concentration increased from $0.1 \mathrm{mM}$ to $1 \mathrm{mM}$ (i.e., [coumarin] : $\left[\mathrm{H}_{2} \mathrm{O}_{2}\right]>1$ ), the signal intensity decreased as depicted in Fig. 2. This can be explained by ineffective collisions between both Fenton's reagent to render ${ }^{\circ} \mathrm{OH}$ and coumarin to
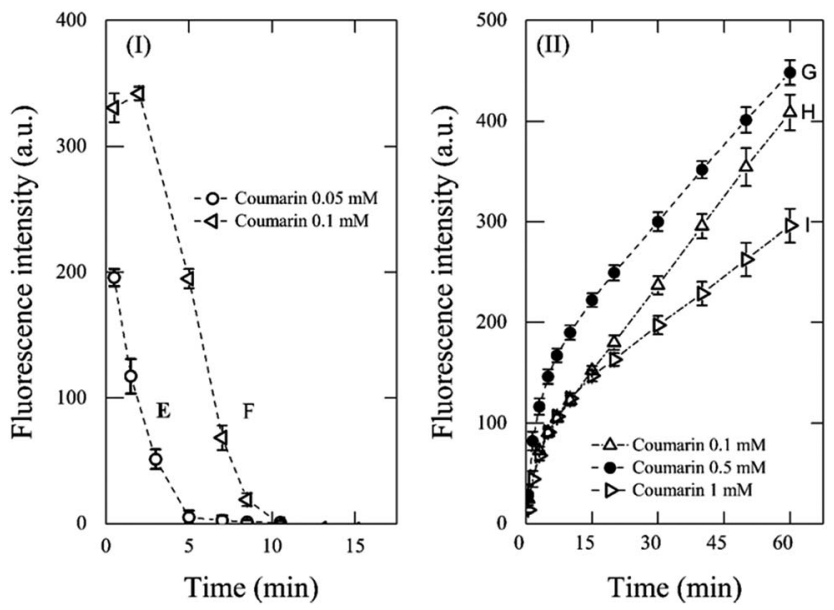

Fig. 2 Effect of coumarin concentration on fluorescence intensity over time for Fenton reaction with $\left[\mathrm{H}_{2} \mathrm{O}_{2}\right]:\left[\mathrm{Fe}^{2+}\right]=10$ : (I) $1 \mathrm{mM} \mathrm{H}_{2} \mathrm{O}_{2}$ and $0.1 \mathrm{mM} \mathrm{Fe}^{2+}$ and (II) $0.1 \mathrm{mM} \mathrm{H}_{2} \mathrm{O}_{2}$ and $0.01 \mathrm{mM} \mathrm{Fe}^{2+}$. 
react with ${ }^{\circ} \mathrm{OH}$, while the reason because the plateau was not reached is due to excess coumarin with respect to Fenton's reagent.

From the above discussions, $1 \mathrm{mM}$ coumarin was determined to be the most suitable concentration to estimate the concentration of ${ }^{\circ} \mathrm{OH}$ (Fig. 1B) for an initial concentration of $1 \mathrm{mM} \mathrm{H}_{2} \mathrm{O}_{2}$ and $0.1 \mathrm{mM} \mathrm{Fe}^{2+}$, which can render suitable kinetic profiles.

\section{Effects of Fenton's reagent ratio and coumarin concentration}

The concentration of ${ }^{\circ} \mathrm{OH}$ was determined to investigate the effect of different Fenton's reagent ratios on the optimal coumarin concentration to be applied (Fig. 3). The left-hand ratios of eqn (7), calculated with different Fenton's reagent ratios, are given in Table 1. Each experiment lasted $60 \mathrm{~min}$. As the $\left[\mathrm{H}_{2} \mathrm{O}_{2}\right]:\left[\mathrm{Fe}^{2+}\right]$ ratio increased (conditions $\mathrm{B}, \mathrm{J}, \mathrm{K}, \mathrm{L}, \mathrm{M}$ described in Table 2), the concentration profile through time for the detection of radicals changed with the [coumarin] : $\left[\mathrm{H}_{2} \mathrm{O}_{2}\right]$ ratio (Fig. 3).

At $\left[\mathrm{H}_{2} \mathrm{O}_{2}\right]:\left[\mathrm{Fe}^{2+}\right]=10$ (Fig. 3I), the ratio [coumarin] : $\left[\mathrm{H}_{2} \mathrm{O}_{2}\right]$ $=1$ determined experimentally concurred with the [coumarin] : $\left[\mathrm{H}_{2} \mathrm{O}_{2}\right]$ ratio calculated using eqn (7) (Table 1). From these experiments, it was noticeable that the system $\mathbf{M}$ exhibited a similar behaviour to conditions $\mathrm{E}$ and $\mathrm{F}$.

In these conditions, the trend across time showed a sudden reduction of the fluorescence intensity after four minutes of reaction time (Fig. S4 $\dagger$ ). At a Fenton's ratio of 100, under conditions $\mathrm{J}$ and $\mathrm{K}$ (Fig. 3II), corresponding to [coumarin] : $\left[\mathrm{H}_{2} \mathrm{O}_{2}\right]$ ratios of 0.1 and 1 , respectively, the experimental [coumarin] : $\left[\mathrm{H}_{2} \mathrm{O}_{2}\right]$ ratio differed from those calculated from eqn (7). In those systems, the predicted [coumarin] : $\left[\mathrm{H}_{2}-\right.$ $\mathrm{O}_{2}$ ] using eqn (7) should be at least $\sim 0.54$ (Table 1 ), suggesting that using 0.54 ratio as optimum [coumarin] : $\left[\mathrm{H}_{2} \mathrm{O}_{2}\right]$ value may render a suitable concentration profile. These results also revealed that the initial amount of ${ }^{\circ} \mathrm{OH}$ detected was around 3.6
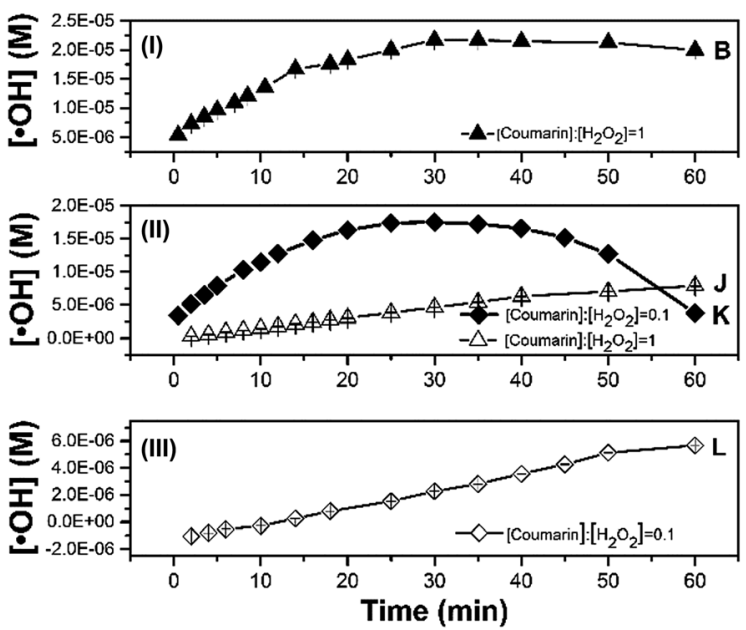

Fig. 3 Time-dependent effect of the $\left[\mathrm{H}_{2} \mathrm{O}_{2}\right]:\left[\mathrm{Fe}^{2+}\right]$ ratio on molar - $\mathrm{OH}$ detection by $1 \mathrm{mM}$ coumarin concentration for 60 min at Fenton's reagent ratios of (I) 10 , (II) 100 and (III) 1000. The size of some error bars are in the same scale than the symbols used. times higher with condition $\mathrm{J}$ than with condition $\mathrm{K}$ around the first four minutes. It should be noted that the maximum amount of ${ }^{\circ} \mathrm{OH}$ in both systems was of the same order of magnitude $\left(\sim 10^{-5} \mathrm{M}\right)$. Thus, the optimal detection of ${ }^{\circ} \mathrm{OH}$ could be achieved at optimal [coumarin] : $\left[\mathrm{H}_{2} \mathrm{O}_{2}\right]$ ratios keeping $\left[\mathrm{Fe}^{2+}\right]$ at its optimal value $(\sim 0.1 \mathrm{mM}$ in this work).

At higher Fenton's ratio of 1000, under condition L (Fig. 3III), the formation of radicals was lower, showing a behaviour similar to that under condition J. This may be related to a slow reaction rate between Fenton's reagent, resulting in less formation of ${ }^{\circ} \mathrm{OH}$. The second order rate constant for hydroxylation of coumarin $\left(5.6 \times 10^{9} \mathrm{M}^{-1} \mathrm{~s}^{-1}\right.$ (ref. 17)) by ${ }^{\circ} \mathrm{OH}$ may imply that a higher concentration of ${ }^{\circ} \mathrm{OH}$ has to be available to promote effective collisions with coumarin. In turn, a higher initial concentration of Fenton's reagent and the adjusted coumarin concentration are required to obtain suitable profiles for ${ }^{\circ} \mathrm{OH}$ detection and quantification. As a result, systems J and $\mathrm{L}$, with a higher Fenton's reagent ratio and non-optimized [coumarin] : $\left[\mathrm{H}_{2} \mathrm{O}_{2}\right]$ ratio, were less efficient at detection radicals over a period of $60 \mathrm{~min}$, without reaching a plateau (quasi-steady-state) zone. Therefore, the fact that the [coumarin]: $\left[\mathrm{H}_{2} \mathrm{O}_{2}\right]$ ratio needs to be optimized as the initial concentration of Fenton's reagent varies may be closely related to the different mechanisms that control the overall reaction as the $\left[\mathrm{H}_{2} \mathrm{O}_{2}\right]:\left[\mathrm{Fe}^{2+}\right]$ changes. ${ }^{41}$ For example, at high $\left[\mathrm{H}_{2} \mathrm{O}_{2}\right]:\left[\mathrm{Fe}^{2+}\right]$ ratios the large amount of $\mathrm{H}_{2} \mathrm{O}_{2}$ added can act as scavenger for the generated ${ }^{\circ} \mathrm{OH}$ (reaction (2)), while at low $\left[\mathrm{H}_{2} \mathrm{O}_{2}\right]:\left[\mathrm{Fe}^{2+}\right]$ ratios the catalytic conversion of $\mathrm{H}_{2} \mathrm{O}_{2}$ to ${ }^{\circ} \mathrm{OH}$ may increase but not the reaction with coumarin because of the promotion of scavenging reactions (reactions (2) and (3)). ${ }^{42}$

Analysis of the amount of ${ }^{\circ} \mathrm{OH}$ detected after one minute of mixing the reagents confirmed this behaviour (Fig. S5 $\dagger$ ). At an initial $\mathrm{H}_{2} \mathrm{O}_{2}$ concentration of $1 \mathrm{mM}$, a higher ${ }^{\circ} \mathrm{OH}$ concentration $\left(7.7 \times 10^{-6} \mathrm{M}\right)$ was achieved during the early phase of reaction (first minutes) with $\left[\mathrm{H}_{2} \mathrm{O}_{2}\right]:\left[\mathrm{Fe}^{2+}\right]=10$ corresponding to condition $\mathrm{B}$, while the amount of ${ }^{\circ} \mathrm{OH}$ detected decreased as the Fenton's reagent ratio increased from 100 to 1000 (Fig. S5I $\dagger$ ), as observed in Fig. 3. At an initial $\mathrm{H}_{2} \mathrm{O}_{2}$ concentration of $10 \mathrm{mM}$, the maximum initial formation of radicals was detected under condition $\mathrm{K}$, and resulted in an analogous magnitude than that obtained with $1 \mathrm{mM} \mathrm{H}_{2} \mathrm{O}_{2}\left(7.7 \times 10^{-6} \mathrm{M}\right.$, Fig. S5II $\left.\dagger\right)$. This again suggests that the coumarin concentration should be optimized in relation to the initial concentration of Fenton's reagent, to achieve suitable reaction rates between ${ }^{\circ} \mathrm{OH}$ and coumarin.

It seems that reasonable predictions of the [coumarin]: $\left[\mathrm{H}_{2} \mathrm{O}_{2}\right]$ ratio can be made using the equations derived from the simplified quasi-steady-state model proposed. These results suggest that the optimum [coumarin]: $\left[\mathrm{H}_{2} \mathrm{O}_{2}\right]$ ratios, initial $\left[\mathrm{H}_{2} \mathrm{O}_{2}\right]$ and iron $\mathrm{Fe}^{2+}$ amount must be adjusted to achieve suitable concentration profiles that allow greater detection of ${ }^{\circ} \mathrm{OH}$ as predicted by the model proposed (Table 1), wherein $7 \mathrm{HC}$ does not react significantly with ${ }^{\circ} \mathrm{OH}$. It should be noted from these results that:

(i) The ratio of Fenton's reagent ratios to generate and detect 'OH using fluorescence (such as $\left[\mathrm{H}_{2} \mathrm{O}_{2}\right]:\left[\mathrm{Fe}^{2+}\right]=10,100$ and 1000) appeared to be less significant than the [coumarin] : $\left[\mathrm{H}_{2} \mathrm{O}_{2}\right]$ ratio as predicted. Those $\left[\mathrm{H}_{2} \mathrm{O}_{2}\right]:\left[\mathrm{Fe}^{2+}\right]$ 
ratios have rendered good level of ${ }^{\circ} \mathrm{OH}$ and are consistent with those typically employed in water treatment processes. ${ }^{39}$

(ii) The [coumarin] : $\left[\mathrm{H}_{2} \mathrm{O}_{2}\right]$ ratio needs to be adjusted as the initial concentration of Fenton's reagent changes; thus, in this work is suggested that the best level of detection of ${ }^{\circ} \mathrm{OH}$ is achieved at $\left[\right.$ coumarin] : $\left[\mathrm{H}_{2} \mathrm{O}_{2}\right]=1$, when $\left[\mathrm{H}_{2} \mathrm{O}_{2}\right]:\left[\mathrm{Fe}^{2+}\right]=10$ and $\mathrm{Fe}^{2+}$ concentration is $0.1 \mathrm{mM}$.

(iii) Under condition $\mathrm{M}$, the theoretical [coumarin] : $\left[\mathrm{H}_{2} \mathrm{O}_{2}\right]$ ratio was not applicable. This bias may be closely related to the fact that: (a) $\mathrm{H}_{2} \mathrm{O}_{2}$ was excessive compared to coumarin, thus leading to excess ${ }^{\circ} \mathrm{OH}$ formation that caused degradation of the reaction product $7 \mathrm{HC}$ into non-fluorescent compounds.

(iv) It was also observed that a ferrous iron concentration of $0.1 \mathrm{mM}$ played a significant role in the amount of ${ }^{\circ} \mathrm{OH}$ detected. This value is in the order of magnitude that other works have found as the optimal operative condition to generate ${ }^{\circ} \mathrm{OH}$ in electro-Fenton systems. ${ }^{20}$

\section{Response of coumarin and DMPO as probes for the detection of ${ }^{\circ} \mathrm{OH}$}

To evaluate the response of different chemical probes at conditions established as suitable from the previous analysis, two independent matrices of experiments were performed using a fixed concentration of chemical probes: $1 \mathrm{mM}$ coumarin and $100 \mathrm{mM}$ DMPO for fluorescence and ESR, respectively. The Fenton's reagent ratio of $\left[\mathrm{H}_{2} \mathrm{O}_{2}\right]:\left[\mathrm{Fe}^{2+}\right]$ was varied from 1 to $10^{4}$, and the equivalent concentration of ${ }^{\circ} \mathrm{OH}$ detected by fluorescence and ESR are depicted accordingly in Fig. 4 and 5. In our previous work, the response of DMPO under a fixed ratio of Fenton's reagent was tested. ${ }^{24}$ In this section, the concentration of chemical probe is kept constant, and the Fenton's reagent ratio is different.

The concentration of ${ }^{\circ} \mathrm{OH}$ detected by fluorescence using coumarin as a probe was measured $22.5 \mathrm{~min}$ after mixing

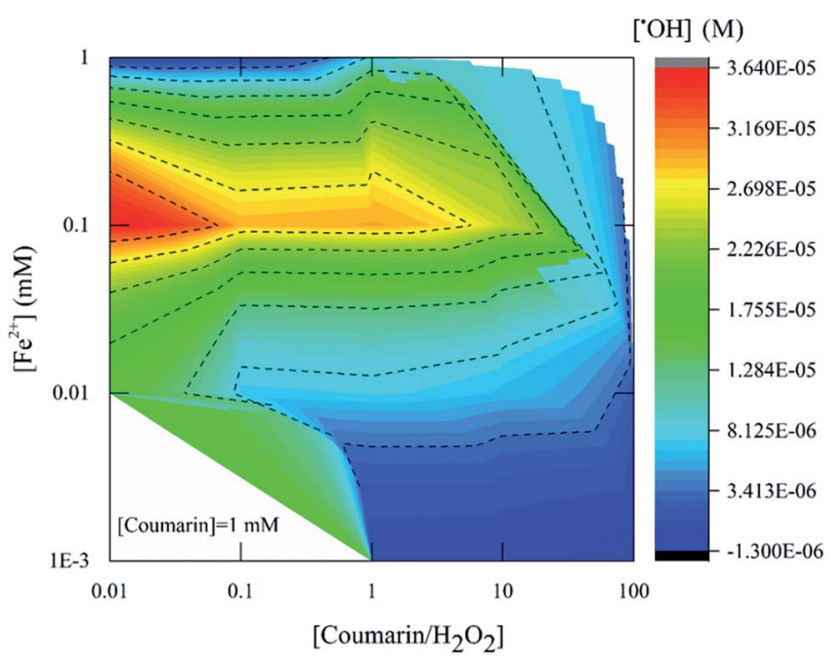

Fig. 4 Equivalent concentration of ${ }^{\circ} \mathrm{OH}$ formed as a function of the Fenton's reagent ratio using $1 \mathrm{mM}$ coumarin. All data were measured 22.5 min after mixing the reagents using 7-hydroxycoumarin (7HC) as a standard. The $x$-axis and $y$-axis are presented on logarithmic scales.

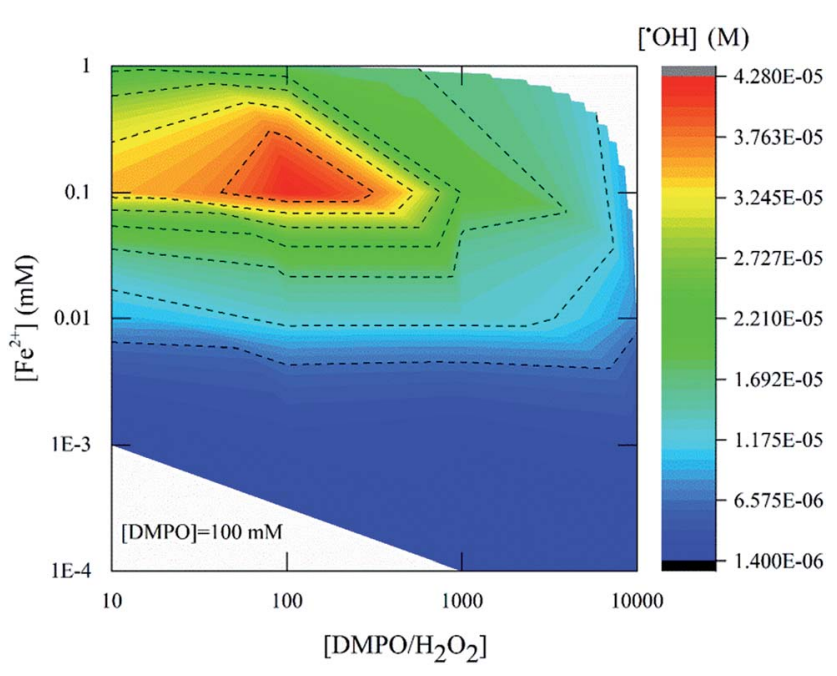

Fig. 5 Equivalent concentration of ${ }^{\circ} \mathrm{OH}$ formed as a function of the Fenton's reagent ratio at constant DMPO adduct probe concentration (100 mM) using TEMPOL as a standard. All data were measured $4 \mathrm{~min}$ after mixing the reagents. The $x$-axis and $y$-axis are presented on logarithmic scales.

Fenton's reagent with coumarin (Fig. 4). The highest product yield was approximately $3.0 \times 10^{-5} \mathrm{M}$ and measured with $\left[\mathrm{H}_{2} \mathrm{O}_{2}\right]:\left[\mathrm{Fe}^{2+}\right]=10$ (condition $\mathrm{B}$ ). For $\left[\mathrm{H}_{2} \mathrm{O}_{2}\right]:\left[\mathrm{Fe}^{2+}\right]=100$, the highest product yield was around $3.0 \times 10^{-5} \mathrm{M}$ (condition $\mathrm{K}$ ) while for $\left[\mathrm{H}_{2} \mathrm{O}_{2}\right]:\left[\mathrm{Fe}^{2+}\right]=1000$ the concentration of ${ }^{\circ} \mathrm{OH}$ detected was $3.6 \times 10^{-5} \mathrm{M}$ (condition $\mathrm{N}$ ). These results also showed that the detection of radicals involved an initial $\mathrm{Fe}^{2+}$ concentration of around $0.1 \mathrm{mM}$, which corresponds to a ratio of 10, 100 and 1000 in respect to $\mathrm{H}_{2} \mathrm{O}_{2}$ concentration (Fig. 5, red zone) as noted previously.

Fig. 5 presents the amount of ${ }^{\circ} \mathrm{OH}$ detected by ESR with different concentrations of Fenton's reagent and using $100 \mathrm{mM}$ DMPO as a probe. The $\left[\mathrm{H}_{2} \mathrm{O}_{2}\right]:\left[\mathrm{Fe}^{2+}\right]$ ratio was varied from 10 to $10^{4}$, and the equivalent ${ }^{\circ} \mathrm{OH}$ amount was measured four min after mixing Fenton's reagent and DMPO. The highest product yield at $\left[\mathrm{H}_{2} \mathrm{O}_{2}\right]:\left[\mathrm{Fe}^{2+}\right]=10$ was $4.2 \times 10^{-5} \mathrm{M}$. With $\left[\mathrm{H}_{2} \mathrm{O}_{2}\right]:\left[\mathrm{Fe}^{2+}\right]=100$, the highest product yield was around $1.3 \times 10^{-5} \mathrm{M}$ while for $\left[\mathrm{H}_{2} \mathrm{O}_{2}\right]:\left[\mathrm{Fe}^{2+}\right]=1000$, the yield was $2.7 \times 10^{-6} \mathrm{M}$. From these results it can be concluded that an effective ${ }^{\circ} \mathrm{OH}$ detection was rendered at a Fenton's reagent ratio of 10 (Fig. 5, red zone).

Finally, a comparison between the coumarin and DMPO results revealed that the magnitude of maximum ${ }^{\circ} \mathrm{OH}$ detected was of the same order of magnitude as $3.6 \times 10^{-5} \mathrm{M}$ and $4.3 \times$ $10^{-5} \mathrm{M}$ respectively. This may imply that at a ratio of $\left[\mathrm{H}_{2} \mathrm{O}_{2}\right]:\left[\mathrm{Fe}^{2+}\right]=10$ and at $[$ chemical $]:\left[\mathrm{H}_{2} \mathrm{O}_{2}\right]$ ratio of at least two orders of magnitude higher than the right side of eqn (7) and (8) would help acquiring a stable analytical signal for measurements of $\mathrm{OH}$. However, some differences can be highlighted: (i) the concentration of chemical probe required for ESR and fluorescence suggests that the ESR method consumes as much as 100 times or more DMPO concentration than the needed with coumarin and (ii) the time required to detect an equivalent molar concentration of ${ }^{\circ} \mathrm{OH}$ is longer for coumarin than for DMPO, $22.5 \mathrm{~min}$ and $4 \mathrm{~min}$ respectively. 
Those times were determined from the kinetic profile, where the system appeared to be stable as it reached a stable state (plateau, Fig. 1B). In addition, the coumarin concentration needed could limit its application under the conditions required in Fenton-based systems.

Therefore further analysis using this technique testing different probes other than non-modified coumarin could be useful as it involves inexpensive reagents, a wide linear range, and is user-friendly compared to the ESR technique.

These data showed the impact of $\left[\mathrm{H}_{2} \mathrm{O}_{2}\right]:\left[\mathrm{Fe}^{2+}\right]$ ratio on the amount of ${ }^{\circ} \mathrm{OH}$ detected. The optimal $\left[\mathrm{H}_{2} \mathrm{O}_{2}\right]:\left[\mathrm{Fe}^{2+}\right]$ ratio for detection of ${ }^{\circ} \mathrm{OH}$ in both techniques was between $\left[\mathrm{H}_{2} \mathrm{O}_{2}\right]:\left[\mathrm{Fe}^{2+}\right]$ $=10$ (Fig. 4 and 5). It is also suggested that the relationship between the chemical probe concentration needed and the ${ }^{\circ} \mathrm{OH}$ formed should be between values of initial concentration of Fenton's reagent that does not promote the further oxidization of the reaction byproduct to be monitored such as $7 \mathrm{HC}$ or DMPO-OH adduct.

\section{Conclusions}

This study investigated the application of both coumarin and DMPO as probes to measure hydroxyl radicals by fluorescence and ESR respectively. Hydroxyl radicals were produced by Fenton's reactions.

The effect of the Fenton's reagent ratio (up to $10^{3}$ ) and the [chemical probe] : $\left[\mathrm{H}_{2} \mathrm{O}_{2}\right]$ ratio on the quantification of hydroxyl radical concentrations was experimentally determined. On the basis of the experimental results, the following conclusions can be drawn:

- Coumarin is a good chemical probe around $1 \mathrm{mM}$ and initial concentration of $1 \mathrm{mM} \mathrm{H}_{2} \mathrm{O}_{2}$ and $0.1 \mathrm{mM} \mathrm{Fe}^{2+}$ because excess can promote either collisions between two coumarins or two fluorophores (7HC) which will render a poor fluorescence signal.

- For reliable quantification of ${ }^{\bullet} \mathrm{OH}$, the [coumarin] : $\left[\mathrm{H}_{2} \mathrm{O}_{2}\right]$ ratio should be two orders greater than the right-hand side of eqn (7) at $\left[\mathrm{H}_{2} \mathrm{O}_{2}\right]:\left[\mathrm{Fe}^{2+}\right]=10$.

- Degradation of $7 \mathrm{HC}$ in the presence of excess ${ }^{\circ} \mathrm{OH}$ may involve a further hydroxylation reaction into non-fluorescent derivatives.

- A ferrous iron concentration of $0.1 \mathrm{mM}$ independently of the chemical probes tested, played a significant role in the amount of ${ }^{\circ} \mathrm{OH}$ generated and detected.

- The optimal $\left[\mathrm{H}_{2} \mathrm{O}_{2}\right]:\left[\mathrm{Fe}^{2+}\right]$ ratio used in the detection of $\mathrm{OH}$ in both techniques fluorescence and ESR was observed to be $\left[\mathrm{H}_{2} \mathrm{O}_{2}\right]:\left[\mathrm{Fe}^{2+}\right]=10$.

- Finally, using DMPO required a higher concentration than coumarin to yield the same amount of ${ }^{\circ} \mathrm{OH}$ detected but resulted being a more reliable probe for detecting ${ }^{\circ} \mathrm{OH}$ under the consideration of this study.

\section{Conflicts of interest}

There are no conflicts to declare.

\section{Acknowledgements}

We would like to thank the support given by the Finnish Funding Agency for Innovation. Thanks to Prof. Enric Brillas for his valuable advice. XD thanks VITO Strategic Research Funds for supporting her contributions to this article, as well as the Strategic Initiative Materials (SIM) in Flanders, within the recyclable materials MaRes program, under grant agreement no. 150626 (Get-A-Met project), and the European Union's Horizon 2020 research and innovation programme under grant agreement no. 654100 (CHPM2030 project).

\section{Notes and references}

1 B. J. Robinson, Hydroxyl radicals in space, Sci. Am., 1965, 213(1), 26-33.

2 G. Zhao, S. Sanchez, O. G. Schmidt and M. Pumera, Poisoning of bubble propelled catalytic micromotors: the chemical environment matters, Nanoscale, 2013, 5(7), 2909-2914.

3 B. P. Chaplin, Critical review of electrochemical advanced oxidation processes for water treatment applications, Environ. Sci.: Processes Impacts, 2014, 16(6), 1182-1203.

4 M. Cheng, G. Zeng, D. Huang, C. Lai, P. Xu, C. Zhang, et al., Hydroxyl radicals based advanced oxidation processes (AOPs) for remediation of soils contaminated with organic compounds: A review, Chem. Eng. J., 2016, 284, 582-598.

5 S. Gligorovski, R. Strekowski, S. Barbati and D. Vione, Environmental Implications of Hydroxyl Radicals $\left({ }^{\circ} \mathrm{OH}\right)$, Chem. Rev., 2015, 115(24), 13051-13092.

6 S.-K. Han, S.-N. Nam and J.-W. Kang, OH radical monitoring technologies for AOP advanced oxidation process, Water Sci. Technol., 2002, 46(11-12), 7-12.

7 J. Radjenovic and D. L. Sedlak, Challenges and Opportunities for Electrochemical Processes as Next-Generation Technologies for the Treatment of Contaminated Water, Environ. Sci. Technol., 2015, 49(19), 11292-11302.

8 A. A. Lewinsky, Hazardous Materials and Wastewater: Treatment, Removal and Analysis, Nova Publishers, 2007, p. 394.

9 E. Brillas, I. Sirés and M. A. Oturan, Electro-Fenton Process and Related Electrochemical Technologies Based on Fenton's Reaction Chemistry, Chem. Rev., 2009, 109(12), 6570-6631.

10 Z.-R. Lin, L. Zhao and Y.-H. Dong, Quantitative characterization of hydroxyl radical generation in a goethite-catalyzed Fenton-like reaction, Chemosphere, 2015, 141, 7-12.

11 M. E. Lindsey and M. A. Tarr, Quantitation of hydroxyl radical during Fenton oxidation following a single addition of iron and peroxide, Chemosphere, 2000, 41(3), 409-417.

12 C. Tai, C. Xiao, T. Zhao, L. Wu and D. Han, Determination of hydroxyl radicals photochemically generated in surface waters under sunlight by high performance liquid chromatography with fluorescence detection, Anal. Methods, 2014, 6(20), 8193-8199. 
13 Q. Xiang, J. Yu and P. K. Wong, Quantitative characterization of hydroxyl radicals produced by various photocatalysts, $J$. Colloid Interface Sci., 2011, 357(1), 163-167.

14 P. Fernández-Castro, M. Vallejo, M. F. San Román and I. Ortiz, Insight on the fundamentals of advanced oxidation processes. Role and review of the determination methods of reactive oxygen species, J. Chem. Technol. Biotechnol., 2015, 90(5), 796-820.

15 A. Abou Dalle, L. Domergue, F. Fourcade, A. A. Assadi, H. Djelal, T. Lendormi, et al., Efficiency of DMSO as hydroxyl radical probe in an Electrochemical Advanced Oxidation Process - Reactive oxygen species monitoring and impact of the current density, Electrochim. Acta, 2017, 246(suppl. C), 1-8.

16 P. R. Marriott, M. J. Perkins and D. Griller, Spin trapping for hydroxyl in water: a kinetic evaluation of two popular traps, Can. J. Chem., 1980, 58(8), 803-807.

17 G. L. Newton and J. R. Milligan, Fluorescence detection of hydroxyl radicals, Radiat. Phys. Chem., 2006, 75(4), 473-478.

18 P. Wardman, Fluorescent and luminescent probes for measurement of oxidative and nitrosative species in cells and tissues: Progress, pitfalls, and prospects, Free Radicals Biol. Med., 2007, 43(7), 995-1022.

19 P. Workman and I. Collins, Probing the Probes: Fitness Factors For Small Molecule Tools, Chem. Biol., 2010, 17(6), 561-577.

20 E. Brillas, M. A. Banos, S. Camps, C. Arias, P.-L. Cabot, J. A. Garrido, et al., Catalytic effect of $\mathrm{Fe}^{2+}, \mathrm{Cu}^{2+}$ and UVA light on the electrochemical degradation of nitrobenzene using an oxygen-diffusion cathode, New J. Chem., 2004, 28(2), 314-322.

21 R. C. Peña, V. O. Silva, F. H. Quina and M. Bertotti, Hydrogen peroxide monitoring in Fenton reaction by using a ruthenium oxide hexacyanoferrate/multiwalled carbon nanotubes modified electrode, J. Electroanal. Chem., 2012, 686(suppl. C), 1-6.

22 C. Ciotti, R. Baciocchi and T. Tuhkanen, Influence of the operating conditions on highly oxidative radicals generation in Fenton's systems, J. Hazard. Mater., 2009, 161(1), 402-408.

23 E. Finkelstein, G. M. Rosen and E. J. Rauckman, Spin trapping. Kinetics of the reaction of superoxide and hydroxyl radicals with nitrones, J. Am. Chem. Soc., 1980, 102(15), 4994-4999.

24 J. M. Fontmorin, R. C. Burgos Castillo, W. Z. Tang and M. Sillanpää, Stability of 5,5-dimethyl-1-pyrroline-N-oxide as a spin-trap for quantification of hydroxyl radicals in processes based on Fenton reaction, Water Res., 2016, 99, 24-32.

25 S. Liu, J. Zhao, K. Zhang, L. Yang, M. Sun, H. Yu, et al., Dualemissive fluorescence measurements of hydroxyl radicals using a coumarin-activated silica nanohybrid probe, Analyst, 2016, 141(7), 2296-2302.

$26 \mathrm{H}$. Czili and A. Horváth, Applicability of coumarin for detecting and measuring hydroxyl radicals generated by photoexcitation of $\mathrm{TiO}_{2}$ nanoparticles, Appl. Catal., B, 2008, 81(3-4), 295-302.
27 M. G. Steiner and C. F. Babbs, Quantitation of the hydroxyl radical by reaction with dimethyl sulfoxide, Arch. Biochem. Biophys., 1990, 278(2), 478-481.

$28 \mathrm{X}$. Yang, X. Xu, J. Xu and Y. Han, Iron Oxychloride (FeOCl): An Efficient Fenton-Like Catalyst for Producing Hydroxyl Radicals in Degradation of Organic Contaminants, J. Am. Chem. Soc., 2013, 135(43), 16058-16061.

29 M. A. Oturan and J.-J. Aaron, Advanced Oxidation Processes in Water/Wastewater Treatment: Principles and Applications. A Review, Crit. Rev. Environ. Sci. Technol., 2014, 44(23), 2577-2641.

30 P. V. Nidheesh and R. Gandhimathi, Effect of solution $\mathrm{pH}$ on the performance of three electrolytic advanced oxidation processes for the treatment of textile wastewater and sludge characteristics, RSC Adv., 2014, 4(53), 27946-27954.

31 R. C. Burgos-Castillo, I. Sirés, M. Sillanpää and E. Brillas, Application of electrochemical advanced oxidation to bisphenol A degradation in water. Effect of sulfate and chloride ions, Chemosphere, 2018, 194, 812-820.

32 N. D. Yordanov and K. Ranguelova, Quantitative electron paramagnetic resonance and spectrophotometric determination of the free radical 4-hydroxy-2,2,6,6tetramethylpiperidinyloxy, Spectrochim. Acta, Part A, 2000, 56(2), 373-378.

33 S. Stoll and A. Schweiger, EasySpin, a comprehensive software package for spectral simulation and analysis in EPR., J. Magn. Reson., 2006, 178(1), 42-55.

34 G. Louit, S. Foley, J. Cabillic, H. Coffigny, F. Taran, A. Valleix, et al., The reaction of coumarin with the $\mathrm{OH}$ radical revisited: hydroxylation product analysis determined by fluorescence and chromatography, Radiat. Phys. Chem., 2005, 72(2), 119-124.

35 K. Takeshita, K. Saito, J. Ueda, K. Anzai and T. Ozawa, Kinetic study on ESR signal decay of nitroxyl radicals, potent redox probes for in vivo ESR spectroscopy, caused by reactive oxygen species, Biochim. Biophys. Acta, Gen. Subj., 2002, 1573(2), 156-164.

36 H. D. C. Carolyn Mottley, 7OJ Oxygen hyperfine structure for the hydroxyl and superoxide radical adducts of the spin traps DMPO, PBN, and 4-POBN, Biochem. Biophys. Res. Commun., 1987, 141(2), 622-628.

37 E. Brillas, A review on the degradation of organic pollutants in waters by UV photoelectro-Fenton and solar photoelectro-Fenton, J. Braz. Chem. Soc., 2014, 25, 393-417.

38 K. Ishibashi, A. Fujishima, T. Watanabe and K. Hashimoto, Quantum yields of active oxidative species formed on $\mathrm{TiO}_{2}$ photocatalyst, J. Photochem. Photobiol., A, 2000, 134(1-2), 139-142.

39 J. J. Pignatello, E. Oliveros and A. MacKay, Advanced Oxidation Processes for Organic Contaminant Destruction Based on the Fenton Reaction and Related Chemistry, Crit. Rev. Environ. Sci. Technol., 2006, 36(1), 1-84.

40 K. G. Fleming, Fluorescence Theory A2-Lindon, in Encyclopedia of Spectroscopy and Spectrometry, ed. C. John, G. E. Tranter and D. W. Koppenaal, Academic Press, Oxford, 3rd edn, 2017, 
pp. 647-653, https:/www.sciencedirect.com/science/article/ pii/B9780128032244003575.

41 J. C. Crittenden and R. R. Trussell, Hand DW. MWH's Water Treatment: Principles and Design. John, Wiley \& Sons, 2012, p. 1921.
42 G. Pliego, J. A. Zazo, P. Garcia-Muñoz, M. Munoz, J. A. Casas and J. J. Rodriguez, Trends in the Intensification of the Fenton Process for Wastewater Treatment: An Overview, Crit. Rev. Environ. Sci. Technol., 2015, 45(24), 2611-2692. 